\title{
Effects of Sunlight Exposure on Grapevine Powdery Mildew Development
}

\author{
Craig N. Austin and Wayne F. Wilcox
}

Department of Plant Pathology and Plant-Microbe Biology, Cornell University, New York State Agricultural Experiment Station, Geneva. 14456.

Accepted for publication 4 May 2012.

\section{ABSTRACT}

Austin, C. N., and Wilcox, W. F. 2012. Effects of sunlight exposure on grapevine powdery mildew development. Phytopathology 102:857-866.

Natural and artificially induced shade increased grapevine powdery mildew (Erysiphe necator) severity in the vineyard, with foliar disease severity 49 to $75 \%$ higher relative to leaves in full sun, depending on the level of natural shading experienced and the individual experiment. Cluster disease severities increased by 20 to $40 \%$ relative to those on check vines when ultraviolet (UV) radiation was filtered from sunlight reaching vines in artificial shading experiments. Surface temperatures of leaves in full sunlight averaged 5 to $8^{\circ} \mathrm{C}$ higher than those in natural shade, and in one experiment, filtering $80 \%$ of all wavelengths of solar radiation, including longer wavelengths responsible for heating irradiated tissues, increased disease more than filtering UV alone. In controlled environment experiments, UV-B radiation reduced germination of $E$. necator conidia and inhibited both colony establishment (hyphal formation and elongation) and maturity (latent period). Inhibitory effects of UV-B radiation were significantly greater at $30^{\circ} \mathrm{C}$ than at 20 or $25^{\circ} \mathrm{C}$. Thus, sunlight appears to inhibit powdery mildew development through at least two mechanisms, i.e., (i) UV radiation's damaging effects on exposed conidia and thalli of the pathogen; and (ii) elevating temperatures of irradiated tissues to a level supraoptimal or inhibitory for pathogen development. Furthermore, these effects are synergistic at temperatures near the upper threshold for disease development.
Powdery mildew, caused by the fungus Erysiphe necator (Schw.) Burr., is a disease ubiquitous to grape growing regions worldwide. Foliar infections negatively affect photosynthesis, can cause premature defoliation, crop reduction, and in severe cases can even lead to vine mortality (19,30). Fruit infections on highly susceptible cultivars can cause complete crop loss if left uncontrolled, but severity levels as low as $3 \%$ can negatively alter wine flavor $(39,49)$ and even inconspicuous levels of disease can promote the development of Botrytis bunch rot and growth of wine-spoilage microorganisms on the berry skins (20). Thus, powdery mildew control is an essential component of any vineyard management program.

Observations have associated an increased development of grapevine powdery mildew with shaded conditions $(10,52)$. Sources of shade can vary within a vineyard, and may include various external (e.g., adjacent wood lots, persistent cloud cover) and/or internal (e.g., tall weeds, dense canopy growth) entities. The light microclimate within the canopy can be further influenced by vine training system, pruning level, row orientation, geographic location of the vineyard, slope, fruit zone leaf removal, or time of year $(8,9,13,14,41)$. Although significant research has been conducted on the light environment within grapevine canopies, these studies have focused primarily on yield and quality components of the fruit. Sunlight exposure on fruit is often associated with improved fruit quality, and promoting it is an important concept in vineyard management $(31,46,47)$.

Inherent with increases in direct sunlight exposure are increases in exposure to ultraviolet (UV) radiation. This component of sunlight (in particular, the UV-B segment, i.e., 290 to $320 \mathrm{~nm}$ wavelength) has numerous effects on biological systems. UV-B

Corresponding author: C. N. Austin

E-mail address: craig.n.austin@usa.dupont.com

http://dx.doi.org/10.1094/PHYTO-07-11-0205

(C) 2012 The American Phytopathological Society has been shown to alter fungal population ratios on plant leaves (34), generally increase fungal mortality $(1,7,23,43,50)$, and change grapevine secondary metabolite production $(27,29)$. Recent reports have further stressed the importance of studying the impacts on agricultural systems of additional UV-B radiation resulting from reduced stratospheric filtering $(7,32,36)$. Although the phytopathological response to UV-B radiation is host/pathogen specific (42), the vast majority of reported studies can be characterized as demonstrating a negative correlation between disease development and UV-B exposure. A second component associated with sunlight that can alter the phylloplane environment is an increase in surface temperature of exposed tissue. Increased surface temperature due to sunlight exposure has been documented on grapes $(6,16,28,33,48)$ and other fruit $(11,17$, $22,45)$, where temperatures of exposed surfaces are often observed to be as much as 5 to $15^{\circ} \mathrm{C}$ above ambient. These studies, however, have focused on the physiological effects on leaves and fruit of these temperature differences, not on their effects on microorganisms growing on the sunlight-exposed surfaces.

Several researchers have reported specific impacts that sunlight exposure can have on the development of grapevine powdery mildew. Chellemi and Marois (10) reported that the cultural practice of basal leaf removal around fruit clusters, intended to benefit fruit quality, resulted in reduced powdery mildew severity on these berries. They concluded that this effect, observed in a commercial vineyard, was due to improved fungicide coverage and inferred that removing basal leaves produced a berry microclimate less conducive for disease development. In comparing training systems and row spacings, Zahavi et al. (52) demonstrated that those that reduced sunlight exposure on clusters were associated with increased powdery mildew severity on the fruit. They attributed this effect on disease development to differences in sunlight distribution within the fruit zone, as there was no measurable difference in air temperature or ambient humidity between the treatments. Keller et al. (26) found that potted 'Chardonnay' and 'Cabernet Sauvignon' vines protected 
from the sun's UV-B radiation had significantly greater levels of foliar powdery mildew than did vines afforded full sun exposure, and attributed this effect to differences in vine physiology between the two treatments.

In controlled environment experiments, Willocquet et al. (51) demonstrated a reduced germination frequency of E. necator conidia, and weaker mycelial growth thereafter, when inoculated leaf discs were exposed to UV-B radiation. Although the authors suggested the importance and potential interaction of both the thermal and photic effects of solar radiation on disease development, they were unable to show a significant interaction between temperature and UV-B radiation. The authors specifically acknowledged the limitations of their study and suggested a need to investigate radiation effects on other processes of fungal infection, particularly sporulation, in addition to the use of whole plant assays in order to (i) more realistically assess solar radiation's effect on pathogen development in the vineyard, and (ii) separate the effects of radiation on the host versus the pathogen.

Thus, our objective was to comprehensively investigate the effects of sunlight exposure on grapevine powdery mildew development through two major, complementary foci. First, in order to address questions and suggestions attendant to the aforementioned studies, we manipulated sunlight distribution on fieldgrown grapevines through natural and artificial shading mechanisms, allowing us to directly observe and quantify the effects on powdery mildew severity of variable sunlight exposure levels and components and to investigate the contributing influence of the host response to these factors. Second, to gain a greater mechanistic understanding of these responses, we used controlled environment chambers to determine the effects of UV-B radiation, temperature, and their interaction on multiple stages of E. necator development, including germination, appressorium formation, hyphal development, and sporulation. Abstracts of this work have been published previously $(3,4)$.

\section{MATERIALS AND METHODS}

Inoculation procedure. Inoculum production. Cultures used for inoculum were sourced from field populations of E. necator collected from local vineyards and maintained constantly on 1- to 3-month-old Vitis vinifera 'Riesling' seedlings in a greenhouse maintained at $25^{\circ} \mathrm{C}$. In May of each year of 2005 to 2008, when ambient temperatures posed no threat to the fungus or host, conidia were multiplied on 2-month-old 'Riesling' seedlings maintained in a covered shadehouse with mesh walls that allowed free air movement; only field experiments were conducted in these years. In 2009 and 2010, inoculum for both field and growth chamber experiments was produced on detached $V$. vinifera 'Chardonnay' leaves, sourced from potted vines planted in 2002, maintained on $1.5 \%$ water agar in petri dishes and incubated at $25^{\circ} \mathrm{C}$ in a growth chamber.

Vineyard experiments. Sporulating leaves were transported to the vineyard, where inoculum was prepared by first agitating the diseased leaves in 50-ml Falcon tubes with a $0.005 \%$ ( $\mathrm{vol} / \mathrm{vol})$ solution of Tween 20 in $\mathrm{dH}_{2} 0$, then adding more Tween solution to bring the spore suspension to a volume necessary to provide $1 \mathrm{ml}$ per inoculated leaf or fruit cluster in that experiment. Subsequent quantification in the lab with the aid of a hemacytometer revealed final concentrations of $5 \times 10^{4}$ to $1 \times 10^{5}$ conidia per $\mathrm{ml}$. For all foliar inoculations described here, only the fourth fully expanded leaf from the shoot terminus was used, in order to minimize any variability due to leaf age (15).

Controlled environment experiments. The fourth expanded leaf from the shoot tip of 7-year-old potted, greenhouse-maintained $V$. vinifera 'Chardonnay' vines was removed and surface disinfested for $10 \mathrm{~min}$ in a $0.5 \% \mathrm{NaOCl}$ solution, triple rinsed with sterile ASTM Type I ultra-pure water, and blotted dry. To maintain hydration, leaves were then placed into double petri plates (39), where each detached leaf remained uncovered but turgid for the duration of the experiment. Conidia from 14-day-old powdery mildew colonies serving as the detached-leaf inoculum source were transferred by brushing them against the disinfested leaves, which were immediately transferred to a growth chamber and subjected to the various treatment regimens described below.

Disease assessment. Powdery mildew severity was assessed by visually rating individual leaves or clusters on a continuous 0 to $100 \%$ scale, based on the estimated proportion of grapevine tissue covered with the pathogen; all ratings were made by C. Austin. Foliar disease was assessed 14 days after inoculation. Disease development on fruit was monitored weekly also beginning 14 days after inoculation, and final severity ratings were made near veraison due to rapid degradation of the most heavily infected clusters and the development of Botrytis bunch rot.

Environment and leaf temperature measurements. In each vineyard, Campbell CR-10X data loggers (Campbell Scientific, Logan, UT) with HMP-45C temperature and relative humidity probes fitted with radiation shields, and LI-200 (LI-COR, Lincoln, NE) pyranometers (400 to $1,100 \mathrm{~nm}$ ) monitored weather parameters. For each treatment, sensors were placed $\approx 1 \mathrm{~m}$ (within the canopy) and $\approx 2 \mathrm{~m}$ (above the canopy) from the ground.

In each vineyard experiment, surface temperatures of 10 arbitrarily chosen leaves were measured weekly at solar noon on days with clear skies, using a Mikron MI-N14 portable infrared thermometer (LumaSense Technologies Inc., Santa Clara, CA). During leaf temperature assessments, the thermometer was angled perpendicular to the center of the leaf at a distance of $\approx 20 \mathrm{~cm}$, thereby evaluating a circular region $\approx 2 \mathrm{~cm}$ in diameter. For each leaf, repeated measurements were made every second until the temperature remained unchanged for $5 \mathrm{~s}$ and then it was recorded.

With assistance from the USDA Natural Resource Ecology Laboratory (Colorado State University, Fort Collins) UV-B monitoring research program, an ultraviolet multifilter rotating shadowband radiometer was used to measure direct, total horizontal, and diffuse UV irradiance at 300, 311, 317, 325, 332, and $368 \mathrm{~nm}$ within each vineyard treatment (full sun, acrylic plastic, and shade cloth) detailed below. The radiometer was positioned in each treatment for 2 weeks during the 2005 and 2006 seasons, UV measurements were made at 10-s intervals, and hourly averages were calculated.

Field trials. Natural shading. The effects of intermittent and constant natural shading on foliar disease severity were observed in an umbrella Kniffen-trained 'Chardonnay' vineyard planted in 1988 near Dresden, NY, utilizing the easternmost row in a northsouth oriented vineyard. Intermittent shading effects were determined in a group of vines immediately west of a $20-\mathrm{m}$ long grouping of $15-\mathrm{m}$ tall pine trees, which completely shaded the vines until approximately 11:30 AM each day during the summer. These vines contrasted with another group $50 \mathrm{~m}$ down the same row, well removed from any external source of shade, establishing one shade treatment of 'tree shade' (+ or - ). In addition, a second form of shading was established by arbitrarily choosing shoots within both groups of vines and either (i) tying them within the interior of the dense canopy, to ensure that they were subjected to this form of constant shade ('canopy shade +') or (ii) selecting them from those on the outer edge of the canopy, fully exposed to the sun ('canopy shade -').

Both levels of canopy shade were combined with both levels of tree shade to produce four treatments which were treated as a completely randomized design experiment. Due to the fixed position of the vines subjected to tree shade, individual treatments were not replicated. Subsampling of each treatment was achieved through separate inoculations where the adaxial surface of the fourth fully expanded leaf on each of 10 shoots per treatment was inoculated in each of two seasons (12 June, 30 June, and 17 July 2005; 9 June, 29 June, and 19 July 2006) using a small portable spray-paint apparatus (Preval, Yonkers, NY). The mean disease 
severity for all leaves sampled in each treatment for each year was calculated and used for analysis. Because the set of vines receiving the tree shading treatment was not replicated, following a suggestion by Perrett and Higgins (37), an intraclass correlation was calculated using maximum likelihood estimates of variance components between and within vines receiving the same treatments.

Pairwise differences between treatment means were then tested using an adjusted estimate of error:

$$
s_{\bar{d}}=\sqrt{2 s_{w}^{2}\left\{\frac{1}{m}\left(\frac{r}{1-r}\right)+\frac{1}{m n}\right\}}
$$

where $s^{2}$ is the within vine error, $r$ is the intraclass correlation coefficient, $m$ is the number of vines receiving the same treatment, and $n$ is the number of observations per vine. For 2005 and 2006, estimates of intraclass correlation coefficients were 0.27 and 0.28 , respectively. Using the adjusted standard errors of mean differences, pairwise comparisons were calculated with $\mathrm{R}$ statistical program using Fisher's least significant differences $(\alpha=$ 0.05).

Fungal diseases in this and other field trials were managed as necessary from bloom until the final disease assessment with minimal sprays of mancozeb and a highly refined petroleum oil (JMS Stylet Oil), chosen for their relative lack of activity against $E$. necator and minimal residual/vapor activity, respectively. Shoots and clusters subject to inoculation were protected within individual plastic bags during each application and the bags were removed immediately after sprays had dried.

Artificial shading. The effects of selective wavelength filtering on fruit disease severity were assessed in two vineyards: (i) a midwire-trained 'Chancellor' vineyard established in 1970 near Geneva, NY; and (ii) a vertical shoot positioned 'Chardonnay' vineyard established in 2005. Within the 'Chancellor' vineyard during each season from 2005 to 2009, free-standing gabled roof frames were constructed $1 \mathrm{~m}$ above four randomly selected threevine panels, with panels defined as adjacent vines in a row bound by the wire-bearing posts within that same row. Three weeks prior to the onset of bloom, four panels each were randomly assigned to receive a top covering of either (i) a double layer of black neutral density shade cloth which filtered $80 \%$ of all wavelengths of sunlight (Griffin Greenhouse \& Nursery Supplies, Tewksbury, MA), or (ii) sheets of 3.1-mm-thick acrylic plastic which filtered $90 \%$ of UV radiation yet allowed $90 \%$ of wavelengths $>400 \mathrm{~nm}$ through (Plexiglas; Altuglas International, Philadelphia, PA). The frame constructed to support these materials was designed to minimize the effect on air movement near the vine, and for the coverings to shade the vines from approximately $1 \mathrm{~h}$ after sunrise until $1 \mathrm{~h}$ before sunset. During the 2007 and 2008 seasons, acrylic plastic roofs were also erected over two randomly chosen fourvine panels in the 'Chardonnay' vineyard. In each vineyard in all seasons, two additional randomly selected panels with unaltered sunlight exposure served as controls. In all experiments, 10 arbitrarily selected clusters (subsamples) per panel (replication) were inoculated 1 week after 50\% anthesis. The mean disease severity for these 10 clusters was calculated for each treatment replicate and used for analysis. Severity ratings were arcsinetransformed and analysis of variance was performed, with exposure treatment as the treatment factor and each panel comprising a plot of the randomized block design. When analysis of variance indicated a significant treatment effect, Tukey's studentized range test was used for means comparison. All analyses were conducted using JMP statistical software (SAS institute, 2007).

Pre-versus postinoculation effects of $U V$ radiation. In order to investigate a possible role of UV radiation on the host response to E. necator, four panels of four vines each were randomly selected in the 'Chardonnay' vineyard near Geneva, NY. One week before foliar inoculation, UV filtering shelters (as described above) were placed over the vines in two of the four panels (UV-), whereas the remaining two were left uncovered and fully exposed to the sun $(\mathrm{UV}+)$. On the day of inoculation, the shelter over one panel was moved to treat the vines in one of the two previously uncovered panels. Thus, all vines in a panel received one of four preinoculation/postinoculation sun-exposure treatments: $\mathrm{UV}+/ \mathrm{UV}+$, $\mathrm{UV}+/ \mathrm{UV}-$, UV-/UV+, and UV-/UV-. Within each treatment, the adaxial surface of four leaves (subsamples) and the abaxial surface of four separate leaves were inoculated as described above. Disease severity on each leaf surface was determined 2 weeks after inoculation, and the mean value of the four subsamples was used to assess the joint effect of UV exposure before and after inoculation. The experiment was repeated three times with inoculation dates of 20 July, 11 August, and 1 September 2010. For each run, treatments were rerandomized among the experimental units. Data were analyzed with $\mathrm{R}$ statistical program using the nlme package for mixed effects models (38).

Controlled environment experiments. The effect of UV-B dosage, and its interaction with temperature, was assessed in controlled environment growth chambers on detached 'Chardonnay' leaves sourced from potted vines and inoculated as described above. One of two different light treatments was established in each chamber: (i) $3.0 \mathrm{~W} / \mathrm{m}^{2}$ of UV-B radiation, supplied by two narrowband fluorescent light bulbs with peak emission at $312 \mathrm{~nm}$ (National Biological Corp., Beechwood, OH), plus photosynthetically active radiation supplied by low-mercury cool white 20W fluorescent bulbs (Grainger, Lake Forest, IL); or (ii) the cool white fluorescent light alone. The UV-B radiation intensity of 3.0 $\mathrm{W} / \mathrm{m}^{2}$ was chosen as representative of peak values measured previously in Geneva, NY on sunny mid-summer afternoons. During exposure to UV-B, detached leaves were covered with a 0.0762-mm-thick acetate film (Du All Drafting and Art Supply, Madison Heights, MI) to prevent UV-C (200 to $290 \mathrm{~nm}$ ) radiation from reaching the sample. UV-B intensity was monitored at the beginning and end of each experiment with a hand-held UVX radiometer fitted with a 310-nm calibrated sensor (UVP LLC, Upland, CA). Experiments were conducted at the temperatures of 20,25 , and $30^{\circ} \mathrm{C}$, chosen for their suboptimal, optimal, and supraoptimal effects on powdery mildew development, respectively (12).

Three separate inoculations in time served as replications for each temperature. For "acute" dose experiments, three leaves (subsamples) per UV-B dose were subjected to the UV-B light source for $0,6,12$, or $24 \mathrm{~h}$ immediately after inoculation, providing a total radiation dosage of $0,64.8,129.6$, or 259.2 $\mathrm{kJ} / \mathrm{m}^{2}$, respectively. Leaves were then transferred to a growth chamber maintained at the same temperature and relative humidity (60 to $80 \%$, dependent on chamber cycling) without UV-B radiation. For "chronic" dose experiments, leaves in all but the check treatment were subjected to a 6-h dose of UV-B immediately after inoculation and then transferred to the growth chamber without UV-B. At daily intervals thereafter, selected leaves were transferred back to the UV-B chambers for additional exposure, so that the final treatments consisted of 6-h exposures on each of $0,1,2$, or 4 consecutive days following inoculation, providing the same total radiation dosage of $0,68.4,129.2$, or $259.2 \mathrm{~kJ} / \mathrm{m}^{2}$, respectively, as applied acutely. A small portion of leaf tissue $\left(\approx 1 \mathrm{~cm}^{2}\right)$ between the superior lateral sinus and the petiolar sinus was removed with a scalpel from each leaf $96 \mathrm{~h}$ after inoculation and the leaves were returned to their controlled environment chambers. The excised tissue was cleared overnight in a 3:1 (vol:vol) ethanol/acetic acid solution, subsequently stained with Coomassie blue, and mounted on slides for assessment of conidia via light microscopy at $100 \times$ magnification.

One hundred conidia on each leaf were classified into one of three developmental categories: (i) no germination; (ii) formation of an appressorium; or (iii) production of a hypha, indicating 
successful establishment of an infection. From this last group in the "chronic" experiment, the hyphal length for each of 10 conidia (subsamples) per leaf was measured using an ocular micrometer. Following these 4-day treatment and assessment periods, all leaves were maintained at the same temperature in the growth chamber without UV-B, and the entirety of each leaf was examined twice daily at $25 \times$ magnification under a stereoscope to determine the latent period for these infections. The latent period was considered complete when the production of the first new conidium was observed. The effects of temperature and UV dose on germination, appressorium formation, hyphal development, hyphal length and latent period were examined by linear regression. Data for each response variable were fitted to separate UV doses, temperature, and interaction terms using a general linear model. JMP statistical software was used for the analysis (SAS Institute, Cary, NC).

\section{RESULTS}

Field trials. Natural shade experiments. In both seasons, shading from external and internal sources increased foliar

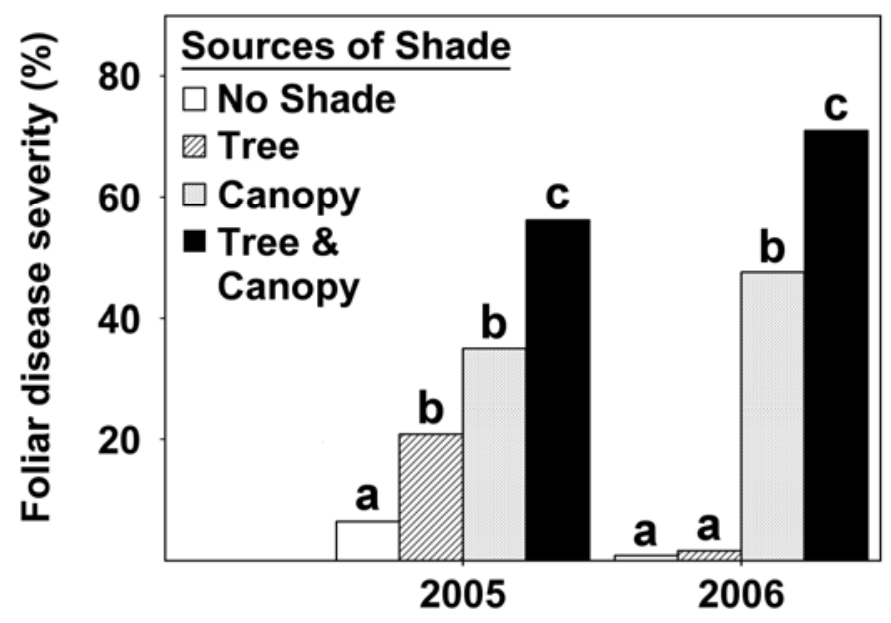

Fig. 1. Percent foliar area infected with powdery mildew on the fourth fully expanded leaf on 'Chardonnay' grapevine shoots (i) receiving full solar radiation, i.e., located on the outer canopy edge on vines well away from a bordering group of trees (No Shade); (ii) on the outer canopy edge but otherwise shaded by an adjacent group of pine trees until 11:30 AM each day (Tree); (iii) located within the interior part of the dense canopies of vines away from the trees (Canopy); and (iv) subjected to both internal canopy shading plus that provided by the adjacent trees (Tree \& Canopy). Disease severity was assessed 14 days after inoculation by visually estimating the percent leaf area covered with signs of the pathogen. Values represent the means of three independent replications, with 10 inoculated leaves (subsamples) per replication in each treatment; bars not labeled with a common letter are significantly different (pairwise comparisons using least significant differences, $\alpha=0.05)$. disease development, with disease severity levels on leaves in the most heavily shaded treatment ('tree and canopy shade') seven and 43-fold higher relative to those afforded full sun exposure ('no shade') in 2005 and 2006, respectively (Fig. 1). However, the effect of the morning shade supplied by the trees alone varied substantially between years, with disease severity on the outside of the canopy threefold higher on vines adjacent to the trees than away from them ('tree' versus 'no shade', respectively) in 2005, whereas there was no difference between these two treatments in 2006. Relative to the 'no shade' treatment, daily interception of solar radiation 400 to $1,100 \mathrm{~nm}$ averaged 74,24 , and $12 \%$ within the 'tree shade', 'canopy shade', and 'tree and canopy shade' treatments, respectively, across the two seasons (Table 1). Among the various treatments, there were no measurable differences in ambient temperature or $\mathrm{RH}$ within the foliar zones (data not shown), but mean leaf temperatures were elevated as much as $7.8^{\circ} \mathrm{C}$ on the sun-exposed versus shaded leaves (Table 2).

Artificial shading. Based on pyranometer readings the double layer of shade cloth filtered out $88 \%$ of UV radiation and $80 \%$ of radiation in the range of 400 to $1,100 \mathrm{~nm}$, whereas the acrylic plastic filtered $87 \%$ of UV radiation but only $9 \%$ of that in the 400 to $1,100 \mathrm{~nm}$ range. In all seasons and at both locations, cluster disease severity was significantly lower in the full sun treatment than in those from which UV radiation was filtered. The acrylic plastic filter (low UV treatment) significantly $(P<0.01)$ increased disease severity from 41 to $62 \%$ in 2006 and 21 to $48 \%$ in 2007 relative to the full sun treatment on the 'Chancellor' vines, and essentially doubled disease severity on the 'Chardonnay' vines in both years of that trial (Fig. 2). There were no measurable differences among treatments in a given experiment regarding air temperature or relative humidity surrounding clusters (data not shown). Midday leaf temperatures were similar

TABLE 2. Mid-day leaf temperature increase $\left({ }^{\circ} \mathrm{C}\right)$ relative to ambient air temperature in the different shading treatments, for all vineyard experiments

\begin{tabular}{llccc}
\hline Experiment, years & Treatment & $n^{\mathrm{a}}$ & Mean $^{\mathrm{b}}$ & Std. dev. \\
\hline 'Chardonnay' & & & & \\
(Dresden), 2005-06 & Full sun & 170 & 6.7 & \pm 1.49 \\
& Trees & 170 & 6.4 & \pm 2.15 \\
& Canopy & 170 & 1.0 & \pm 0.99 \\
& Trees and canopy & 170 & 0.8 & \pm 0.98 \\
'Chancellor' & Full sun & 410 & 4.7 & \pm 1.60 \\
2005-09 & UV filter & 410 & 4.9 & \pm 1.78 \\
& Shade cloth & 410 & 1.6 & \pm 0.85 \\
'Chardonnay' & & & & \\
(Geneva), 2007-08 & Full sun & 130 & 7.8 & \pm 1.50 \\
& UV filter & 130 & 7.5 & \pm 1.78 \\
\hline
\end{tabular}

a Total number of measurements across all years. Temperatures were determined at solar noon on clear days with no wind throughout each growing season.

${ }^{\mathrm{b}}$ Mean increase of leaf temperature above ambient temperature $\left({ }^{\circ} \mathrm{C}\right)$.

TABLE 1. Percent interception ( \pm standard error) of non-UV solar radiation (400 to $1,100 \mathrm{~nm}$ wavelengths) within various treatments in the 'Chancellor' and 'Chardonnay' (Dresden) vineyards relative to that in full sun ${ }^{\mathrm{a}}$

\begin{tabular}{|c|c|c|c|c|c|}
\hline \multirow[b]{2}{*}{ Year } & \multicolumn{2}{|c|}{ 'Chancellor' $(\%)^{\mathrm{b}}$} & \multicolumn{3}{|c|}{ 'Chardonnay', Dresden $(\%)^{\mathrm{c}}$} \\
\hline & UV filter & Shade cloth & Tree shade & Canopy shade & Tree and canopy shade \\
\hline 2005 & $\mathrm{Na}$ & $20 \pm 0.4$ & $74 \pm 2.2$ & $26 \pm 0.9$ & $14 \pm 0.5$ \\
\hline 2006 & $97 \pm 2.3$ & $24 \pm 1.1$ & $74 \pm 2.6$ & $22 \pm 0.8$ & $10 \pm 0.6$ \\
\hline 2007 & $91 \pm 1.2$ & $25 \pm 0.6$ & $\ldots$ & $\ldots$ & $\ldots$ \\
\hline
\end{tabular}

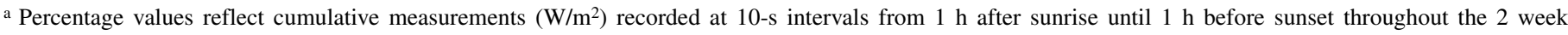
duration of each experiment plus one standard error of the mean.

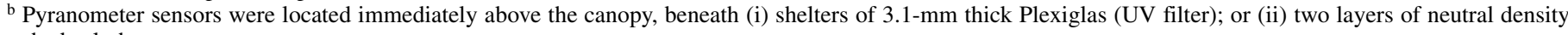
shade cloth.

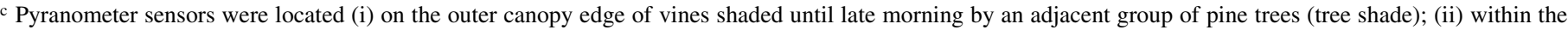
interior of the dense canopy of vines away from the trees (canopy shade); and (iii) within the interior of the dense canopy of vines shaded by the trees (tree and canopy shade). 
to the ambient air temperature for leaves in the shade cloth treatment, but were on average $5^{\circ} \mathrm{C}$ higher on the sun-exposed leaves, with or without UV filtering (Table 2). Cluster disease severity was significantly greater on 'Chancellor' vines beneath the shade cloth than on those beneath the acrylic plastic filters in 2006, although there was no significant difference between these two treatments in 2008 and 2009 (Fig. 2).

Pre- versus postinoculation effects of $U V$ radiation. The preinoculation UV treatment had no effect on the subsequent development of powdery mildew, with disease severity on the adaxial surface of leaves preexposed to UV-filtered sunlight averaging $16.0 \%$ across both postinoculation treatments versus $17.1 \%$ for those exposed to full sunlight $(P=0.70)$; the same comparison on the abaxial leaf surface was $27.5 \%$ versus $32.7 \%$, respectively $(P=0.24)$. In contrast, the 2 -week postinoculation UV treatment had a highly significant effect $(P<0.001)$, with $31.3 \%$ disease severity on the adaxial surface of leaves exposed to UV-filtered sunlight (when averaged across both pre-inoculation treatments) versus only $1.9 \%$ for those fully exposed to natural sunlight (Table 3). On the abaxial leaf surface, disease severity was nearly twice as high on vines provided UV-filtered sunlight than on those exposed to natural sunlight $(P=0.003)$ (Table 3$)$. There was no interaction between the pre- and postinoculation treatments for either the adaxial or abaxial leaf surface $(P=0.83$ and 0.32 , respectively).

Controlled environment experiments. Increases in acute UVB dosage significantly $(P<0.0001)$ impacted conidial germination, reducing it approximately two- to threefold at the highest dose relative to the untreated control at all three temperatures. The impact was equally significant with respect to the frequency of conidia that successfully established infection within 4 days after inoculation, as indicated by development of a primary hypha $(P<$ $0.0001)$, falling to $<3 \%$ following a continuous exposure of $24 \mathrm{~h}$

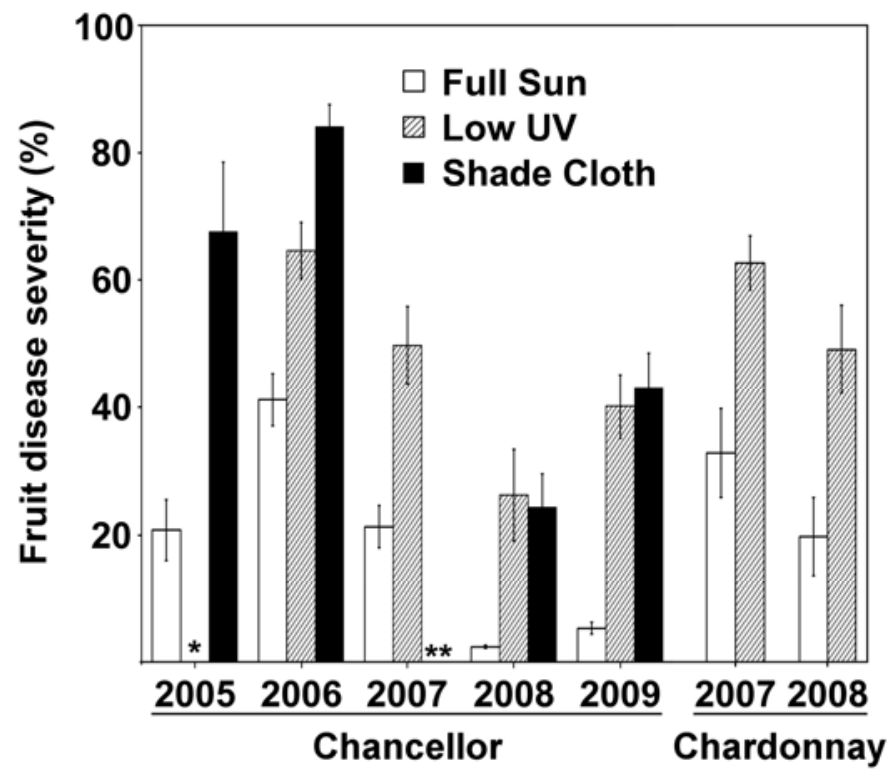

Fig. 2. Percent cluster area with powdery mildew on 'Chancellor' and 'Chardonnay' vines receiving (i) full solar radiation (Full Sun); (ii) sunlight from which $87 \%$ of ambient UV radiation was filtered with acrylic plastic (Plexiglas) shelter units (Low UV); or (iii) sunlight from which $80 \%$ of ambient radiation in the 400 to $1,100 \mathrm{~nm}$ range and $88 \%$ of ambient UV radiation was filtered via two layers of neutral density shade cloths (Shade Cloth). Disease severity was assessed by visually estimating the percent cluster area covered with signs of the pathogen near the time of veraison. Values represent the means for 10 clusters in each of four replicate plots per treatment, and error bars represent one standard error of the mean. * signifies no low UV treatment in 2005 and $* *$ signifies less than $10 \%$ fruit set occurred in the shade cloth treatment in 2007 , so no fruit disease ratings were obtainable. at 20 and $25^{\circ} \mathrm{C}$ and $12 \mathrm{~h}$ at $30^{\circ} \mathrm{C}$. Temperature and UV-B dosage were significantly interactive with respect to both conidial germination frequency, and primary hyphae development $(P=$ 0.05 , and 0.02 , respectively). Temperature alone had a significant $(P=0.003)$ effect on germination frequency $(P=0.0005)$ and the establishment of successful infections $(P=0.003)$, with the latter occurring most frequently at $25^{\circ} \mathrm{C}$ absent the highest UV-B dose. Indeed, the only insignificant parameter for the acute UV-B exposure treatments was a lack of interaction between temperature and UV-B dose on appressorial formation $(P=0.12)$ (Table 4; Fig. 3).

Frequencies of both conidial germination and hyphal formation were also impacted significantly $(P<0.001$ and 0.001 , respectively) by UV-B doses applied in a chronic manner (Fig. 3, Table 4). However, the responses were somewhat less intense following chronic rather than acute exposure, as indicated by the magnitude of the slopes of the comparable regression lines for these two variables (Table 4). For example, the highest dosage of 259.2 $\mathrm{kJ} / \mathrm{m}^{2}$ allowed 10 to $55 \%$ of conidia to establish infection and form a hypha when applied across the three temperatures in a chronic manner versus virtually no such development when applied acutely (Fig. 3C and F). Temperature alone significantly $(P<0.0001)$ impacted the percentage of conidia that germinated, formed appressoria, or formed primary hyphae, with greater frequencies at $20^{\circ} \mathrm{C}$ than at the other two temperatures (Fig. 3, Table 4). There was no significant interaction between temperature and UV dose with respect any of these three variables (Table 4).

Repeated exposure to $64 \mathrm{~kJ} / \mathrm{m}^{2}$ UV-B over the first $96 \mathrm{~h}$ following inoculation significantly reduced the development of hyphae $(P<0.0001)$ from germinated conidia (Fig. 4). Compared to the unexposed controls, four daily UV-B exposures (259.2 $\mathrm{kJ} / \mathrm{m}^{2}$ in total) at 20,25 , and $30^{\circ} \mathrm{C}$, resulted in mean reductions of 66,54 , and $65 \%$ in hyphal length, respectively. Temperature also had a highly significant $(P<0.0001)$ effect on this first stage of colony growth, with hyphal lengths greatest at $25^{\circ} \mathrm{C}$ followed by those at 20 and $30^{\circ} \mathrm{C}$, respectively. There was a highly significant interaction $(P<0.0001)$ between temperature and UV-B dose on hyphal elongation (Table 4), reflecting the relatively poor elongation at $30^{\circ} \mathrm{C}$ even in the absence of UV-B treatment (Fig. 4) and the consequently flatter response to various dosages at this temperature, which is also reflected by the slopes of the regression lines at the three temperatures (Table 4).

At each of the three temperatures, the latent period increased linearly $(P<0.0001)$ in response to UV-B dosage and in a similar manner whether applied acutely or chronically (Fig. 5). At $25^{\circ} \mathrm{C}$, the latent period was increased by $40 \%$ relative to the no UV-B check treatment (i.e., from 5 to 7 days) following the maximum total dosage of $259.2 \mathrm{~kJ} / \mathrm{m}^{2}$, under both the acute and chronic exposure regimes. Similarly, the same dosage increased latent

TABLE 3. Foliar powdery mildew severity ( \pm standard error) on vines subjected to varying UV exposure regimes before and after inoculation with Erysiphe necator conidia

\begin{tabular}{lccccc}
\hline & \multicolumn{4}{c}{ Postinoculation exposure } \\
\cline { 2 - 3 } $\begin{array}{l}\text { Pre-inoculation } \\
\text { exposure }\end{array}$ & \multicolumn{2}{c}{ Abaxial inoculations } & & \multicolumn{2}{c}{ Adaxial inoculations } \\
\cline { 2 - 3 } \cline { 5 - 6 } & UV- & UV+ & & UV- & UV+ \\
\hline UV- & $38.1 \pm 6.0$ & $16.9 \pm 4.0$ & & $31.0 \pm 3.1$ & $1.0 \pm 0.4$ \\
UV+ & $38.9 \pm 3.7$ & $26.4 \pm 0.6$ & & $31.5 \pm 2.1$ & $2.7 \pm 0.7$ \\
\hline
\end{tabular}

${ }^{a}$ For 1 week prior to inoculation, vines were either shielded from UV radiation by acrylic plastic filters erected above them (UV-) or were left fully exposed to the sun (UV+).

b Immediately following inoculation, vines were either protected from UV radiation by acrylic plastic filters erected above them (UV-) or were left fully exposed to the sun (UV+). Values represent mean disease severities (\% area symptomatic) determined 2 weeks after inoculating each of four leaves on either the abaxial or adaxial surface, across all three replications of the experiment $(n=12)$. 
periods by approximately 1 to 2 days at the suboptimal temperature of $20^{\circ} \mathrm{C}$, under both regimes. In contrast, the latent period more than doubled following exposure to this highest UV-B dosage at $30{ }^{\circ} \mathrm{C}$, from 7 days with no UV-B exposure to 16 and 15 days following acute and chronic exposures, respectively. A highly significant interaction between temperature and UV-B exposure level was found for both the acute and chronic exposure $(P=0.0003$ and 0.007 , respectively) regimes (Table 4). Comparison of regression line slopes (Table 4 ) for each temperature indicated a significantly $(P<0.001)$ different rate of increase in latent period in response to UV-B radiation at $30^{\circ} \mathrm{C}$ versus both 20 and $25^{\circ} \mathrm{C}$, for both acute and chronic exposure.

\section{DISCUSSION}

Our results conclusively demonstrate that sunlight significantly inhibits growth of E. necator and development of grapevine powdery mildew, not only in controlled environment conditions but also in vineyards. By quantifying the effect of variable levels of natural shade, and through the use of various artificial shading materials to isolate two specific components of sunlight (i.e., UV radiation and the heating of exposed tissues by longer wavelengths), we documented a consistent increase in disease severity in response to increased levels of shade and showed that both components can contribute to this effect. Although the association between light exposure and disease development has been noted in previous studies $(10,51,52)$, our results are the first to demonstrate the relationship between disease severity and various forms and levels of shading across multiple vineyards. Furthermore, by utilizing controlled environment experiments we were able to establish the role of UV-B in reducing disease development through its negative effects on various initial stages of pathogenesis as well as colony maturation, and its interaction with elevated temperatures.

Reductions in UV radiation on leaves by natural shading or on fruit via shade cloth or UV-filtering acrylic plastic increased powdery mildew severity in all vineyard experiments. UV-B radiation has been shown to alter fungal populations on plant leaves (34) and be detrimental to the survival of multiple fungi $(1,7,23,43,50)$. However, powdery mildew fungi appear to be particularly vulnerable to UV radiation, due to their generally superficial growth habit and lack of pigmentation. Specific host/pathogen interactions reviewed in the literature $(33,42)$ indicate that UV-B exposure after inoculation can often hinder infection. Willocquet et al. (51) demonstrated reduced conidial germination and weaker mycelial growth when grapevine leaf discs inoculated with $E$. necator were exposed to UV-B radiation, and this was supported by our findings.

In our study, differential disease severities associated with varying UV-B exposures were observed 2 weeks (leaves) to

TABLE 4. Regression analysis of various measures of powdery mildew development as a function of UV-B dose following inoculation with Erysiphe necator conidia, under two exposure regimes at three different temperatures (data presented in Figures 3, 4, and 5 as indicated)

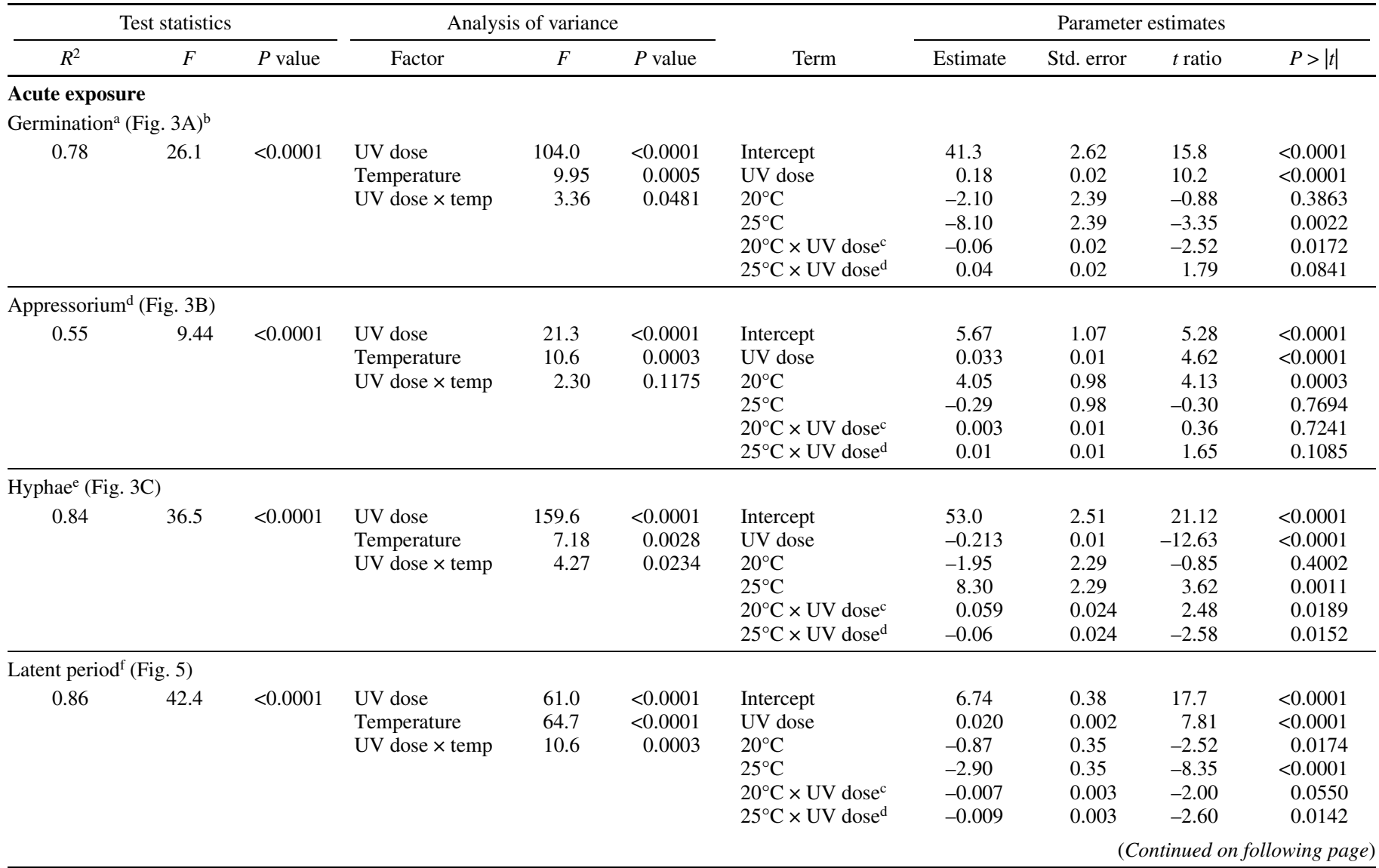

\footnotetext{
a Analysis for the percentage of conidia that remained ungerminated $96 \mathrm{~h}$ after inoculation.

b Parenthetical designations following individual response variables refer to the specific figure in which the analyzed data are presented.

c The effective UV dose for interaction term is calculated by subtracting the mean UV dose $\left(113.4 \mathrm{~kJ} / \mathrm{m}^{2}\right)$ for each respective temperature.

d Analysis for the percentage of conidia that germinated and formed an appressorium within $96 \mathrm{~h}$ after inoculation.

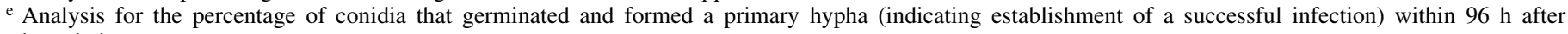
inoculation.

f Analysis for latent period duration (days) following inoculation.

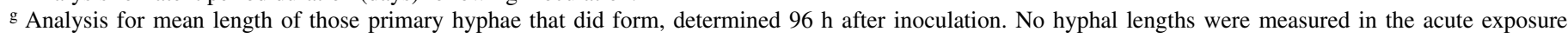
treatment.
} 
2 months (clusters) after vineyard inoculations. These were consistent with the effects of variable UV-B doses on E. necator conidia and germlings that we recorded within $96 \mathrm{~h}$ after inoculating leaves under controlled environment conditions. Thus, it appears that the disease-suppressing effects of UV-B first become operative at the very start of the infection process. Our controlled-environment results, in which increasing UV-B radiation doses (both acute and chronic) progressively reduced both germination frequency and the proportion of germinated spores that established infection (produced a hypha), are generally consistent with those of Willocquet et al. (51), although the doses used in our study spanned a greater range than did theirs (0 to $259.2 \mathrm{~kJ} / \mathrm{m}^{2}$ versus 0 to $56.1 \mathrm{~kJ} / \mathrm{m}^{2}$, respectively). Unlike this previous study, however, we observed that the negative effect of acute UV-B exposure on the proportion of conidia able to establish infections and produce hyphae within $96 \mathrm{~h}$ after inoculation appeared to be somewhat buffered at the suboptimal temperature of $20^{\circ} \mathrm{C}$ relative to the optimum developmental temperature of $25^{\circ} \mathrm{C}$. Conversely, the damaging effect of UV-B on these processes was exacerbated at the supraoptimal temperature of $30^{\circ} \mathrm{C}$. The impact of UV-B radiation was greater at the initial stages, specifically appressorial formation, of the infection process when a given dose was applied acutely rather than chronically, perhaps due to the activity of cellular repair mechanisms between radiation exposure periods in the latter regimen. Indeed, in the chronic exposure treatments, which for the higher UV-B doses are more representative of exposure patterns likely to occur in the field, UV-B effects on appressorium formation were in- consistent and insignificant $(P=0.25)$, although they were highly significant $(P<0.0001)$ for measures of subsequent colony development after infections had been established (i.e., hyphal length and latent period).

Although Willocquet et al. (51) postulated an increased effect of UV-B at higher temperatures, they were unable to confirm this hypothesis, perhaps due to the limited temperature regulation obtained within and between their experiments. However, in our study we found that temperature and UV-B exposure were highly interactive in their effects on both the early stages of colony development (hyphal formation and elongation) and subsequent maturity (latent period duration), whereas there was no significant interaction with respect to conidial germination or appressorium formation. The synergistic effects of UV-B and high temperatures in limiting disease development are of particular practical importance since in the field, those tissues receiving the most UV-B exposure from direct sunlight are also those most likely to have their temperatures elevated into a range where this interaction will occur.

There is extensive documentation that sunlight exposure increases surface temperature on grapes $(6,16,28,33,48)$ and other fruit $(11,17,45)$, and of the effects this has on berry physiology. The effects that this phenomenon may have on disease development do not appear to be widely documented, however. From our own measurements, supported by the aforementioned literature, it was evident that the temperatures of leaves and fruit in the sun were often above optimum for E. necator development and in some cases approached or exceeded those detrimental to

TABLE 4. (Continued from previous page)

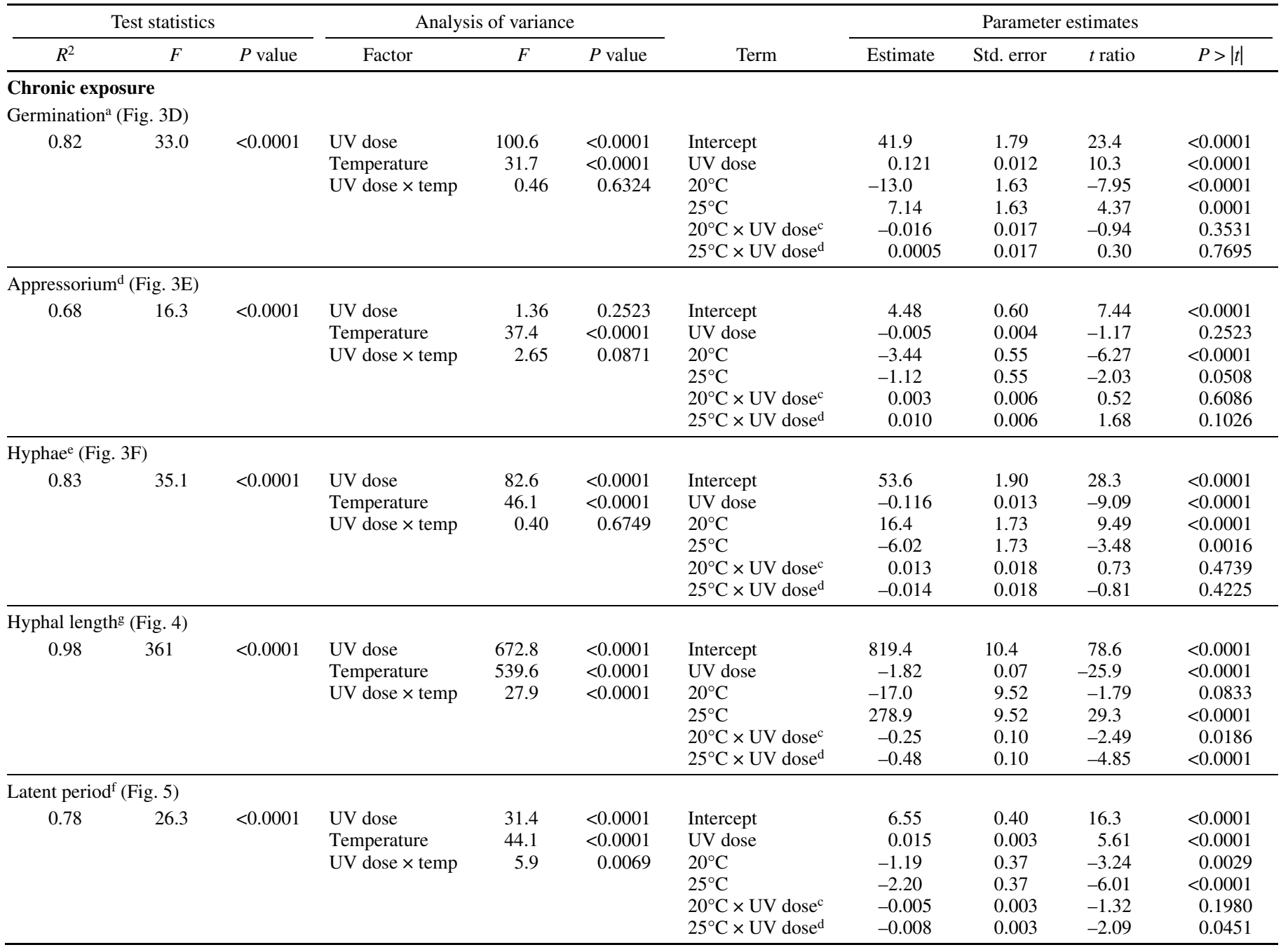



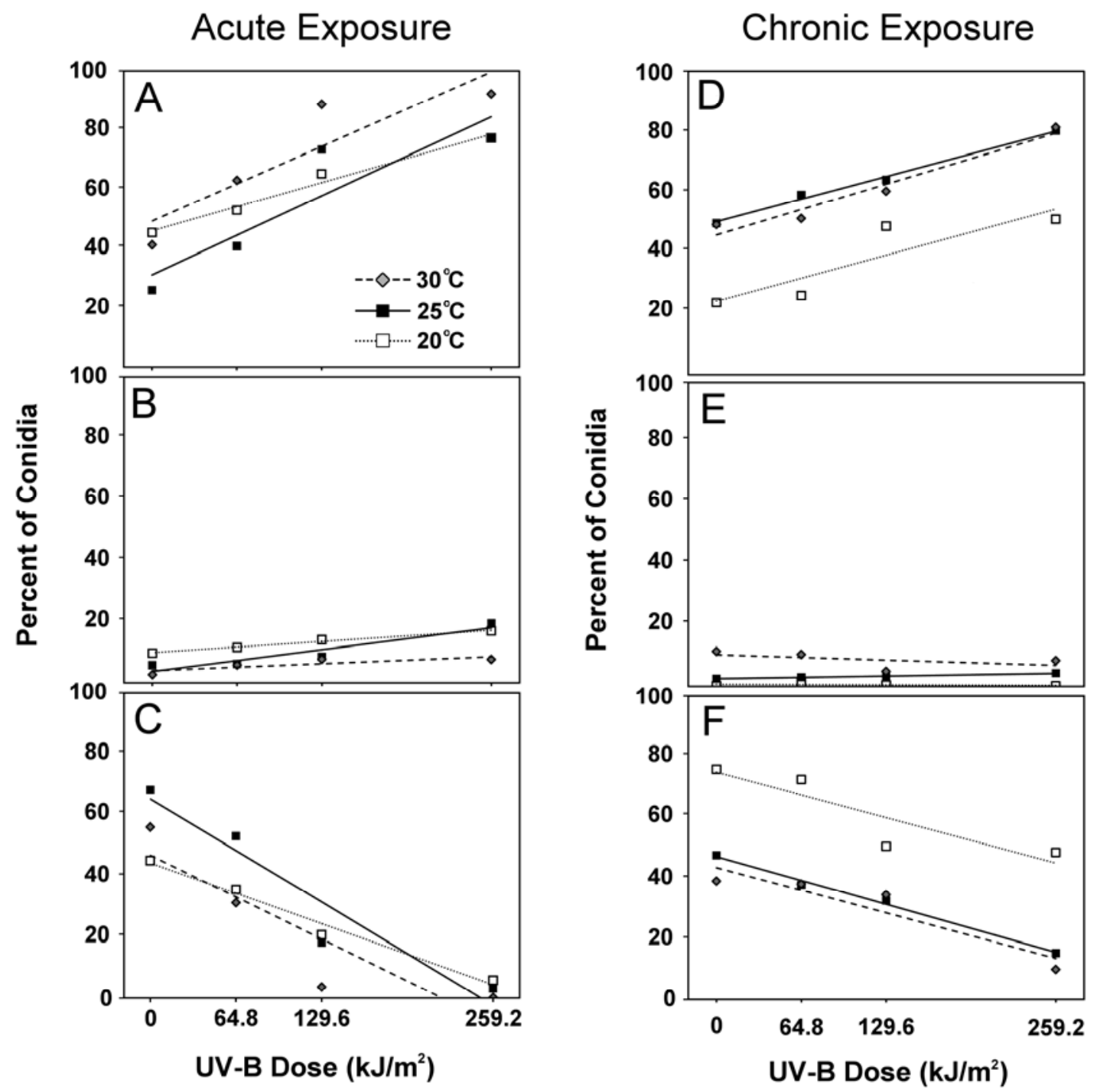

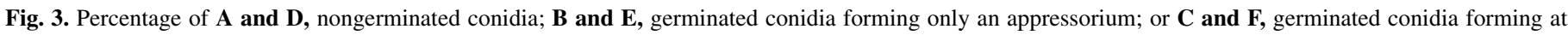

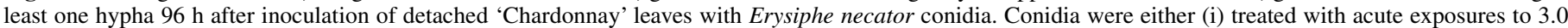

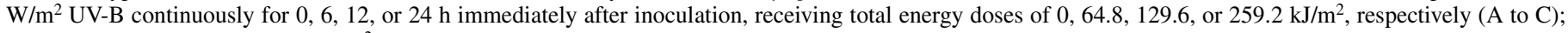

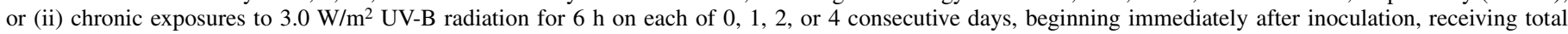

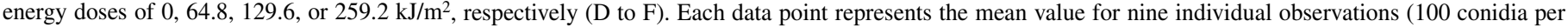
leaf $\times$ three leaves [subsamples] per experiment $\times$ three repeated experiments). Statistics are presented in Table 4 .

the fungus, while concurrently the temperatures of shaded leaves and fruit remained near ambient and closer to the range ideal for pathogen growth. Indeed, both Delp (12) and Willocquet et al. (51) discussed a similar temperature effect of sunlight exposure on irradiated grape tissues and questioned whether it might influence the development of powdery mildew upon them, although neither provided data in support of this hypothesis. Nevertheless, in our Chancellor vineyard in 2006, fruit disease severity was significantly greater on vines beneath shade cloth (all wavelengths filtered) than on those beneath acrylic plastic (UV filtered but longer, heating wavelengths admitted), demonstrating the impact that sunlight-induced surface temperature increases can play on powdery mildew development. Although this effect was not observed on cluster infections in all seasons, infections of leaves, which often are better exposed to the sun than fruit, or of clusters on vines in regions where ambient temperatures are regularly near the upper threshold for powdery mildew development, may experience a more consistent inhibitory effect of elevated surface temperatures. It should be noted that Delp's (12) seminal work on powdery mildew responses to temperature was conducted in controlled environment chambers in the absence of sunlight, and thus did not distinguish the potential differences between ambient and host surface temperatures, nor the interactive effects between higher temperatures and UV radiation likely to occur in the field.

In an obligate parasite-host interaction such as E. necator-Vitis sp., separating the effects of temperature and UV-B exposure on one participant from those on the other is not only critical for our understanding of the phenomena but also difficult to achieve. Keller et al. (26) provided data suggesting that exposure to UV-B radiation in sunlight can reduce the grapevine's susceptibility to infection by this pathogen. Results from our vineyard experiment in which vines either received or were denied the UV spectrum from ambient sunlight for 1 week prior to inoculation did not support this concept. However, exposure of leaves to UV radiation after inoculation reduced disease severity on both their adaxial and abaxial surfaces. As UV radiation does not pass through the leaf translaminarly and is poorly scattered by vegetation, the abaxial data suggest that UV radiation might inhibit powdery mildew development indirectly to some extent, through induction of a plant-mediated response that must be initiated and/or maintained postinoculation. Nevertheless, a far greater UV-associated reduction in disease severity occurred on the adaxial surface, suggesting that direct negative effects of UV 


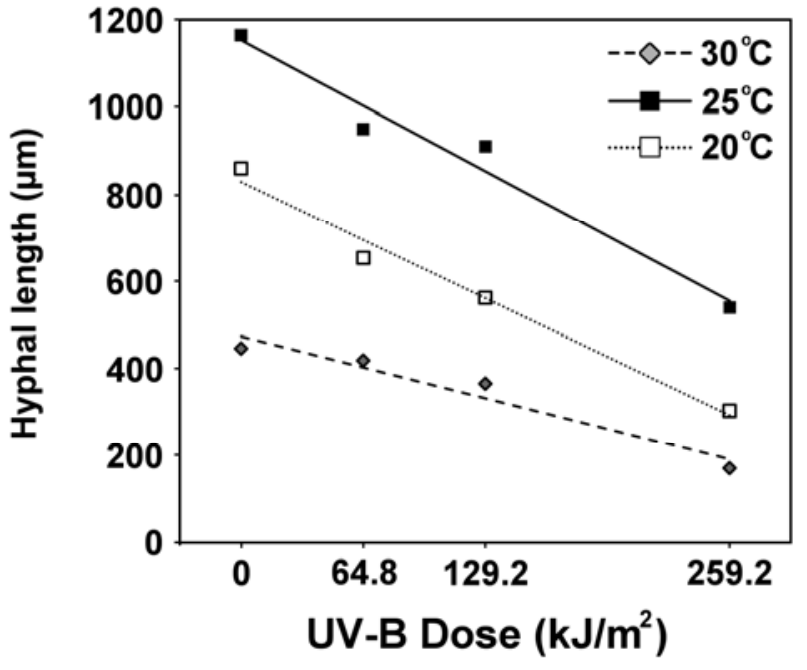

Fig. 4. Mean maximum length of primary hyphae $96 \mathrm{~h}$ after inoculation with Erysiphe necator conidia. For each temperature, conidia were exposed to 3.0 $\mathrm{W} / \mathrm{m}^{2}$ UV-B radiation for $6 \mathrm{~h}$ on each of $0,1,2$, or 4 consecutive days beginning immediately after inoculation, receiving total energy doses of 0 , $64.8,129.6$, or $259.2 \mathrm{~kJ} / \mathrm{m}^{2}$, respectively. Ten hyphae were measured on each of three leaves (subsamples) per replicate, and the experiment was replicated twice $(n=60)$. Statistics are presented in Table 4 .

radiation on the pathogen and/or their interaction with a hostmediated response are likely responsible for most of the reduced powdery mildew development associated with sunlight-exposed tissues in the field. Previous studies on various host plants yielded variable responses to preinoculation UV-B exposure, with disease severity increasing in some pathosystems and decreasing in others $(32,42)$. Jordan $(24)$ has reviewed how UV-B can alter reactive oxygen species generation, signal transduction, and changes in gene expression, including pathogenicity-related (PR) proteins, in grapevines.

Management of powdery mildew is an essential component of any viticultural operation. All commercial grape varieties are susceptible to this disease to some degree, particularly those of $V$. vinifera, by far the most important cultivated Vitis species worldwide. Our results suggest that reducing both external and internal sources of shading can be significantly beneficial components of an integrated-crop-management strategy for contending with the disease. Indeed, viticultural practices promoting sunlight penetration into the vine canopy have been shown to limit disease development under field conditions $(2,5,10,52)$. Powdery mildew growth models have been developed $(9,18,43)$ as have forecasting models $(21,25)$ to help growers assess disease risk and guide them with respect to fungicide application timing. Existing models are heavily reliant upon measurement of ambient air temperature, yet our results show that not only is the relationship between air and host tissue temperature affected by the latter's sunlight exposure status, but that the quantitative effect of temperature on pathogen development is influenced, sometimes pronouncedly, by its degree of UV-B exposure. Thus, microclimates or weather conditions that provide UV-B exposure levels especially deviant from the norm (e.g., persistent cloudy weather in a region that is typically sunny, and vice versa) may be more or less favorable for disease development than would otherwise be predicted, particularly if this factor was not accounted for in model development. Similarly, this may be particularly worthy of consideration when applying existing models for use in regions substantially different from those of their origin or when devising new models. For example, Moyer et al. (35) recently found that the best environmental measure for predicting the progress of a grapevine powdery mildew epidemic was pan evaporation (depth of water evaporated from an open container thereof), which

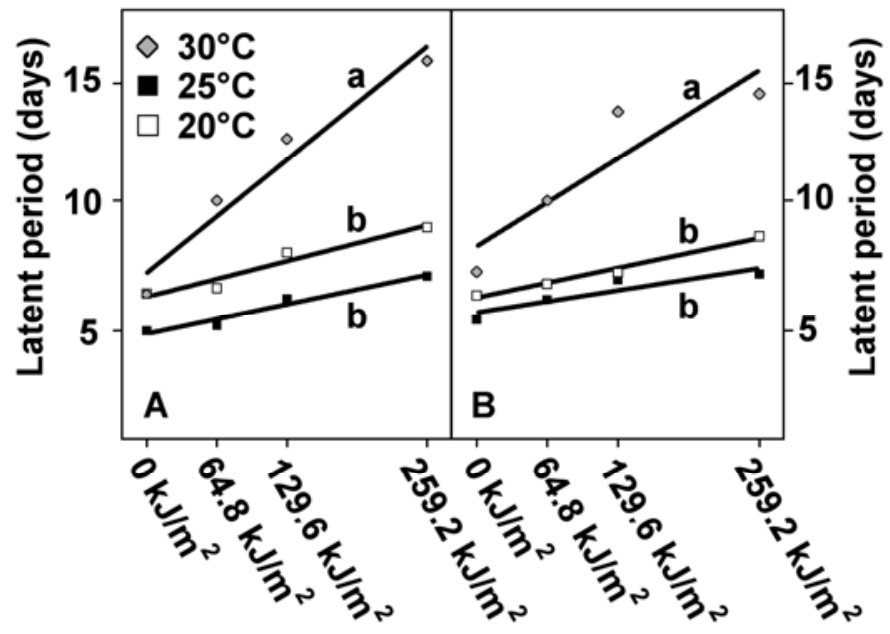

Fig. 5. The latent period of Erysiphe necator as a function of temperature and UV-B exposure. Conidia on excised 'Chardonnay' leaves were exposed to four different doses of UV-B radiation at 20,25 , or $30^{\circ} \mathrm{C}$, under acute and chronic exposure regimes. A, Conidia and leaves received acute exposures to UV-B, supplied at an intensity of $3.0 \mathrm{~W} / \mathrm{m}^{2}$, for $0,6,12$, or $24 \mathrm{~h}$ immediately after inoculation, for a total UV-B dose of $0,64.8,129.6$, or $259.2 \mathrm{~kJ} / \mathrm{m}^{2}$, respectively. B, Conidia and leaves received 6-h exposures to UV-B supplied at this same intensity on each of $0,1,2$, or 4 consecutive days beginning immediately after inoculation, providing the same respective cumulative doses as in the acute treatments. Each of three leaves (subsamples) for all temperature $\times$ UV-B combinations was monitored for conidia production from the developing powdery mildew colonies starting 4 days postinoculation; the latent period was deemed complete once the first new conidium was observed. Acute and chronic experiments were repeated three times for each temperature and data were pooled for analysis. Within A and B, lines not labeled with a common letter have significantly different slopes $(P<0.001)$. Statistics are presented in Table 4.

integrates the influence of ambient air temperature, relative humidity, and solar radiation. Although our study was limited to the E. necator/grapevine pathosystem, the general biological principles involved suggest that the importance of UV-B exposure, surface temperature, and their interaction on pathogen development may also have applicability to other pathosystems, especially those of various unpigmented powdery mildew fungi, whose thallus growth is predominantly on its host surface.

\section{LITERATURE CITED}

1. Arabi, M. I. E., and Jawhar, M. 2003. Germinability of Cochliobolus sativus conidia exposed to solar radiation. J. Phytopathol. 151:620-624.

2. Austin, C. N., Grove, G. G., Meyers, J. M., and Wilcox, W. F. 2011. Powdery mildew severity as a function of canopy density: Associated impacts on sunlight penetration and spray coverage. Am. J. Enol. Vitic. 62:23-31.

3. Austin, C. N., Lakso, A. N., Seem, R. C., Riegel, D. G., Gadoury, D. M., and Wilcox, W. F. 2008. Impact of sunlight and its components on severity of grapevine powdery mildew. (Abstr.) Phytopathology 98(suppl.):S15.

4. Austin, C. N., Lakso, A. N., Seem, R. C., Riegel, D. G., Grove, G. G., and Wilcox, W. F. 2009. Inhibition of grapevine powdery mildew by improved vineyard sunlight exposure. (Abstr.) Phytopathology 99(suppl.):S6.

5. Austin, C. N., and Wilcox, W. F. 2011. Effects of fruit zone leaf removal, training system, and variable irrigation on powdery mildew development on Vitis vinifera L. Chardonnay. Am. J. Enol. Vitic. 62:193-198.

6. Bergqvist, J., Dokoozlian, N., and Ebisuda, N. 2001. Sunlight exposure and temperature effects on berry growth and composition of Cabernet Sauvignon and Grenache in the central San Joaquin Valley of California. Am. J. Enol. Vitic. 52:1-7.

7. Björn, L. O. 2006. Stratospheric ozone, ultraviolet radiation, and cryptogams. Biol. Conserv. 135:326-333.

8. Caldwell, M. M., Robberecht, R., and Flint, S. D. 1983 Internal filters: Prospects for UV-acclimation in higher plants. Physiol. Plant 58:445-450.

9. Calonnec, A., Cartolaro, P., Naulin, J.-M., Bailey, D., and Langlais, M. 2008. A host-pathogen simulation model: Powdery mildew of grapevine. Plant Pathol. 57:493-508. 
10. Chellemi, D. O., and Marois, J. J. 1992. Influence of leaf removal, fungicide applications, and fruit maturity on incidence and severity of grape powdery mildew. Am. J. Enol. Vitic. 43:53-57.

11. Chen, L. S., Li, P., and Cheng, L. 2009. Comparison of thermotolerance of sun-exposed peel and shaded peel of 'Fuji' apples. Environ. Exp. Bot. 66:110-116.

12. Delp, C. 1954. Effect of temperature and humidity on the grape powdery mildew fungus. Phytopathology 44:615-626.

13. Dokoozlian, N. K., and Kliewer, W. M. 1995. The light environment within grapevine canopies. I. Description and seasonal changes during fruit development. Am. J. Enol. Vitic. 46:209-218.

14. Dokoozlian, N. K., and Kliewer, W. M. 1995. The light environment within grapevine canopies. II. Influence of leaf area density on fruit zone light environment and some canopy assessment parameters. Am. J. Enol. Vitic. 46:219-226.

15. Doster, M. A., and Schnathorst, W. C. 1985. Effects of leaf maturity and cultivar resistance on development of the powdery mildew fungus on grapevines. Phytopathology 75:318-321.

16. Downey, M. O., Dokoozlian, N. K., and Kristic, M. P. 2006. Cultural practice and environmental impacts on the flavonoid composition of grapes and wine: A review of recent research. Am. J. Enol. Vitic. 57:257268.

17. Ferguson, I. B., Snelgar, W., Lay-Yee, M., Watkins, C. B., and Bower, J. H. 1998. Expression of heat shock protein genes in apple fruit in the field. Aust. J. Plant Physiol. 25:155-163.

18. Gadoury, D. M., Seem, R. C., Magarey, P. A., Emmett, R., and Magarey, R. 1995. Effects of environment and fungicides on epidemics of grape powdery mildew: Considerations for practical model development and disease management. Vitic. Enol. Sci. 52:225-229.

19. Gadoury, D. M., Seem, R. C., Pearson, R. C., and Wilcox, W. F. 2001. Effects of powdery mildew on vine growth, yield, and quality on Concord grapes. Plant Dis. 85:137-140.

20. Gadoury, D. M., Seem, R. C., Wilcox, W. F., Henick-Kling, T., Conterno, L., Day, A., and Ficke, A. 2007. Effects of diffuse colonization on grape berries by Uncinula necator on bunch rots, berry microflora, and juice and wine quality. Phytopathology 97:1356-1365.

21. Gubler, W. D., Rademacher, M. R., Vasquez, S. J., and Thomas, C. S.1999. Control of powdery mildew using the UC Davis powdery mildew risk index. APSnet Feature. Published online by The American Phytopathological Society, St. Paul, MN.

22. Helyes, L., Lugasi, A., and Pék, Z. 2007. Effects of natural light on surface temperature and lycopene content of vine ripened tomato fruit. Can. J. Plant Sci. 87:927-929.

23. Isard, S. A., Dufault, N. S., Miles, M. R., Hartman, G. L., Russo, J. M., de Wolf, E. D., and Morel, W. 2006. The effect of solar irradiance on mortality of Phakopsora pachyrhizi urediniospores. Plant Dis. 90:941-945.

24. Jordan, B. R. 2002. Molecular response of plant cells to UV-B stress. Funct. Plant Biol. 29:909-916.

25. Kast, W. K. 1997. A step by step risk analysis (SRA) used for planning sprays against powdery mildew (OidDiag-System). Vitic. Enol. Sci. 52:230-231.

26. Keller, M., Rogiers, S. Y., and Schultz, H. R. 2003. Nitrogen and ultraviolet radiation modify grapevines' susceptibility to powdery mildew. Vitis. 42:87-94

27. Keller, M., and Torres-Martinez, N. 2004. Does UV radiation affect winegrape composition? Acta Hort. 640:313-319.

28. Kliewer, W. M., and Lider, L. A. 1968. Influence of cluster exposure to the sun on the composition of Thompson Seedless fruit. Am. J. Enol. Vitic. 19:175-184.

29. Kolb, C. A., Kaser, M. A., Kopecky, J., Zotz, G., Riederer, M., and Pfundel, E. E. 2001. Effects of natural intensities of visible and ultraviolet radiation on epidermal ultraviolet screening and photosynthesis in grape leaves. Plant Physiol. 127:863-875.

30. Lakso, A. N., Pratt, C., Pearson, R. C., Pool, R. M., Seem, R. C., and Welser, M. J. 1982. Photosynthesis, transpiration, and water use efficiency of mature grape leaves infected with Uncinula necator (powdery mildew). Phytopathology 72:232-236.
31. Lee, S. H., Seo, M. J., Riu, M., Cotta, J. P., Block, D. E., Dokoozlian, N. K., and Ebeler, S. E. 2007. Vine microclimate and norisoprenoid concentration in cabernet sauvignon grapes and wines. Am. J. Enol. Vitic. 58:291-301.

32. Manning, W. J., and von Tiedemann, A. 1995. Climate change: potential effects of increased atmospheric carbon dioxide $\left(\mathrm{CO}_{2}\right)$, ozone $\left(\mathrm{O}_{3}\right)$, and ultraviolet-B (UV-B) radiation on plant diseases. Environ. Pollut. 88:219245.

33. Millar, A. A. 1972. Thermal regime of grapevines. Am. J. Enol. Vitic. 23:173-176

34. Moody, S. A., Paul, N. D., Björn, L. O., Callaghan, T. V., Lee, J. A., Manetas, Y., Rozema, J., Gwynn-Jones, D., Johanson, U., Kyparissis, A., and Oudejans, A. M. C. 2001. The direct effects of UV-B radiation on Betula pubescens litter decomposing at four European field sides. Plant Ecol. 154:27-36.

35. Moyer, M. M., Gadoury, D. M., Cadle-Davidson, L., Dry, I. B., Wilcox, W. F., and Seem, R. C. 2010. Development of an advisory system for grapevine powdery mildew in Eastern North America: A reassessment of epidemic progress. Plant Health Progress doi:10.1094/PHP-2010-052602-SY.

36. Paul, N. D. 2000. Stratospheric ozone depletion, UV-B radiation and crop disease. Environ. Pollut. 108:343-355.

37. Perrett, J. J., and Higgins, J. J. 2006. A method for analyzing unreplicated agricultural experiments. Crop Sci. 46:2482-2485.

38. Pinheiro, J., Bates, D., DebRoy, S., Sarkar, D., and the R Development Core Team. 2010. Nlme: Linear and nonlinear mixed effects models. $\mathrm{R}$ package version 3.1-97. R Foundation for Statistical Computing, Vienna, Austria.

39. Pool, R. M., Pearson, R. C., Welser, M. J., Lakso, A. N., and Seem, R. C. 1984. Influence of powdery mildew on yield and growth of Rosette grapevines. Plant Dis. 68:590-593.

40. Quinn, J. A., and Powell, C. C. 1981. Identification and host range of powdery mildew of Begonia. Plant Dis. 65:68-70.

41. Reynolds, R. G., and Van den Heuvel, J. E. 2009. Influence of grapevine training systems on vine growth and fruit composition: A review. Am. J. Enol. Vitic. 60:251-268.

42. Roberts, M. R., and Paul, N. D. 2006. Seduced by the dark side: integrating molecular and ecological perspectives on the influence of light on plant defense against pests and pathogens. New Phytol. 170:677-699.

43. Rotem, J., Wooding, B., and Aylor, D. E. 1985. The role of solar radiation, especially ultraviolet, in the mortality of fungal spores. Phytopathology 75:510-514

44. Sall, M. A. 1979. Epidemiology of grape powdery mildew: A model. Phytopathology 70:338-342.

45. Schroeder, C. A. 1965. Temperature relationships in fruit tissues under extreme conditions. Proc. Am. Soc. Hort. Sci. 87:199-203.

46. Smart, R. E. 1985. Principles of grapevine canopy microclimate manipulation with implications for yield and quality. A review. Am J. Enol. Vitic. 36:230-239.

47. Smart, R. E. 1991. Sunlight Into Wine: A Handbook for Winegrape Canopy Management. Winetitles, Adelaide.

48. Smart, R. E., and Sinclair, T. R. 1976. Solar heating of grape berries and other spherical fruits. Agric. Meteorol. 17:241-259.

49. Stummer, B. E., Francis, I. L., Zanker, T., Lattey, K. A., and Scott, E. S. 2005. Effects of powdery mildew on the sensory properties and composition of Chardonnay juice and wine when grape sugar ripeness is standardized. Aus. J. Grape Wine Res. 11:66-76.

50. Ulevičius, V., Pečiulytė, D., Lugauskas, A., and Andriejauskienè. 2004. Field Study on changes in viability of airborne fungal propagules exposed to UV radiation. Environ. Toxicol. 19:437-441.

51. Willocquet, L., Colombet, D., Rougier, M., Fargues, J., and Clerjeau, M. 1996. Effects of radiation, especially ultraviolet $\mathrm{B}$, on conidial germination and mycelial growth of grape powdery mildew. Eur. J. Plant Pathol. 102:441-449.

52. Zahavi, T., Reuveni, M., Scheglov, D., and Lavee, S. 2001. Effect of grapevine training systems on development of powdery mildew. Eur. J. Plant Pathol. 107:495-501. 